\title{
12 TIPS AGAR BERHASIL MENJALANI PROSES WIRAUSAHA
}

\section{Ria Jainul Mufitah}

Universitas Nahdlatul Ulama Sidoarjo riajainul@tutanota.com

Pengusaha terbiasa menghadapi tantangan. Pada kenyataannya, banyak dari kehidupan profesional mereka terdiri dari mencoba untuk mengatasi satu tantangan demi satu. Tetapi jika Anda seorang wirausaha, salah satu tantangan terbesar yang mungkin Anda hadapi adalah bagaimana menemukan kembali diri Anda ketika Anda telah mencapai ujung jalan dan perlu membawa hidup dan karier Anda ke arah yang baru. Bagi banyak dari kita, kita datang untuk mendefinisikan diri kita dan seluruh keberadaan kita dengan satu hal begitu lama. Kita makan, tidur, dan menghirup satu hal, satu proyek, atau satu identitas itu. Tetapi suatu hari ketika itu berakhir dan pergi, karena satu dan lain alasan, kami sering kali tidak yakin apa yang harus dilakukan atau bagaimana untuk melanjutkan. Lagipula, 
jika Anda seorang wirausaha sejati, Anda akan selalu memiliki tujuan yang ingin Anda capai, dan meskipun tidak pernah mudah untuk menciptakan kembali diri Anda, itu semua yang dapat Anda lakukan. Ada beberapa langkah yang harus diambil dan tips yang harus diperhatikan untuk membantu Anda melalui proses kewirausahaan Anda.

\section{Mendelegasikan}

Dunia dan masyarakat membutuhkan kewirausahaan (Setyawati, Purnomo, Irawan, Tamyiz, \& Sutiksno, 2018). Anda tahu di mana letak kekuatan Anda (dan apa yang Anda lakukan yang menumbuhkan bisnis Anda), tetapi Anda hanya satu orang. Jika ada tugastugas kasar yang menghabiskan waktu Anda yang berharga, pekerjakan mereka. Menyewa asisten paruh waktu atau bantuan dari situs freelancer untuk menghapusnya (DiScala, 2017).

\section{Berencana untuk Mengubah Rencana}

Edupreneur atau educational entrepreneur berasal dari dua kata yaitu education bermakna pendidikan dan entrepreneur bermakna pengusaha atau wirausahawan. Ada juga yang menyamakan 
istilah edupreneur dengan istilah teacherpreneur (Purnomo, 2017). Pendidikan wirausaha bertujuan menyampaikan ilmu dan mentransformasi orang lain menjadi pengusaha yang lebih baik (Fidiana, Istiana, Rosyidah, \& Purnomo, 2017). Pendididkan membantu perencanaan. Tidak punya rencana itu bodoh. Apa yang terburuk: memiliki rencana dan tetap menggunakannya ketika itu jelasjelas salah arah. Sebagai seorang wirausaha, Anda harus belajar untuk gesit dan berpikiran terbuka. Tetap berpegang pada senjata Anda ketika usus Anda memberitahu Anda untuk melakukannya. Tapi jangan terlalu kaku: jika Anda memblokir wawasan yang masuk, Anda akan mengikuti peta jalan yang salah dan itu bisa berakibat fatal (Mérineau, 2017).

\section{Istirahat}

Untuk menghindari kejenuhan mental, Anda harus memaksakan diri untuk istirahat kadang-kadang. Ini bisa berarti mematikan telepon Anda setiap malam, mengabaikan email akhir pekan, atau berlibur panjang setiap tahun. Ketika Anda seorang wirausahawan, mudah "hidup" setiap saat. Namun, ini dapat menghambat aliran kreatif Anda dan memengaruhi efektivitas Anda. Luangkan 
waktu untuk melakukan dekompresi secara teratur - pikiran Anda (dan bisnis) akan berterima kasih (DiScala, 2017).

\section{Pelajari Cara Gagal}

Senantiasa belajar dan bekerja keras. Bersabarlah dengan masalah, sesungguhnya didalam kesulitan ada kemudahan (Sholichah, Istiqomah, Rosyidah, \& Purnomo, 2017). Musuh terburuk pengusaha adalah kebanggaan. Pengusaha sukses sebelumnya pernah mengalami kegagalan monumental. Jika Anda tidak dapat menerima kegagalan sejak awal, jangan memulai proyek Anda. Kegagalanlah yang membangun pengusaha sukses, dengan memberi mereka pengetahuan dan keterampilan yang mustahil diperoleh sebaliknya. Kami menyebutnya pengalaman hidup. Sederhana seperti itu. Pikirkan tentang itu, siapa yang akan Anda hubungi jika Anda mengalami sakit hati yang hebat? Teman Anda yang telah tinggal bersama selama 14 tahun atau orang yang dicampakkan 6 kali? Lihat! Hidup adalah sumber pengetahuan dan kebijaksanaan, dalam bisnis seperti dalam kehidupan pribadi Anda. Beberapa wirausahawan memberi tahu saya: "Tidak mungkin proyek saya tidak akan berhasil — itu 
akan sangat besar!" Ketika saya mendengarnya, itu sering merupakan pertanda yang sangat buruk, karena wirausahawan belum mengakui kemungkinan kegagalan. Dalam kasus seperti itu, saya meminta pengusaha untuk menuliskan segala sesuatu yang bisa salah dengan proyek mereka dan menjelaskan kepada saya bagaimana perasaan mereka ketika menghadapi kegagalan pahit. Mengakui kemungkinan gagal dan mengalami kegagalan adalah jalan yang diperlukan untuk sukses. Pada akhirnya, mengetahui cara bangkit kembali adalah yang terpenting (L'Écuyer, 2016).

\section{Lebih Keras, Lebih Baik, Lebih Cepat, Lebih Kuat Bersama}

Bermitra Sangat menggoda untuk ingin membangun semuanya sendiri untuk mendapatkan semua nilai. Tetapi dengan sumber daya yang terbatas, seringkali tidak realistis dan tidak efisien. Bermitra dengan startup lain di ruang Anda yang sedang membangun teknologi pelengkap bisa menjadi strategi yang tepat yang akan menambah banyak nilai pada penawaran Anda hampir secara instan. Ini adalah langkah yang murah dan efektif untuk mempercepat peta jalan 
produk Anda dan membantu Anda mencapai pasar lebih cepat (dan belajarlah dalam prosesnya!) (Mérineau, 2017).

\section{Branding adalah Persepsi yang Anda Buat di Pasar untuk Menarik Audiens Target Anda}

Sebuah merek yang bagus dimulai dengan memahami siapa Anda dan apa yang Anda perjuangkan, memahami pasar Anda, dan memahami posisi Anda. Apa persepsi yang perlu Anda buat untuk menarik audiens target Anda? Persimpangan kredibilitas, diferensiasi dan keunikan, dan relevansi adalah tempat Anda ingin memposisikan merek Anda secara terbaik (Basu, 2018).

\section{Muncul Setengah Pekerjaan}

Dapatkan di pesawat atau di mobil Anda dan muncul sendiri ketika itu penting. Kita hidup di dunia yang hebat di mana alat-alat virtual seperti Skype dan Slack memungkinkan kita untuk bekerja dengan siapa pun di dunia. Namun, ketika semuanya ada di jalur, tidak ada yang seperti pertemuan tatap muka yang baik. Itulah cara Anda dapat benar-benar mengikat dan mewujudkan sesuatu. Jadi, lompatlah ke 
pesawat itu saat dihitung, Anda tidak akan pernah menyesalinya (Mérineau, 2017).

\section{Gunakan Grup Media Sosial untuk Membangun Komunitas di Sekitar Bisnis Anda}

Grup Facebook kami bukan hanya sebuah grup, ini adalah komunitas dan kami telah mengembangkannya secara organik. Kami membantu mempromosikan orang lain, kami sering merayakan wanita lain, dan benarbenar mempraktikkan kolaborasi daripada kompetisi. Kami pikir kami telah mengembangkan pengikut yang kuat tidak hanya karena kami menciptakan konten yang baik, logis, tetapi kami telah menciptakan merek tepercaya yang membangkitkan semangat, tetapi juga menyenangkan (Basu, 2018).

\section{Untuk Tuhan}

Wirausaha senantiasa harus selalu berpegang teguh pada sifat yang dimiliki oleh Rasul yaitu jujur, amanah, fathana, siddiq selain itu juga harus bermodal ikhas, karena Allah ingin agamanya itu di amalkan (Munjidah, Zannah, Purnomo, \& Rosyidah, 2017). Pemimpin wirausaha harus seperti kata orang 
dahulu, yaitu Ngeluruk Tanpo Bolo, Menang Tanpo Ngasorake, Sakti Tanpo Aji-Aji, Sugeh Tanpo Bolo (Maula, Mufidah, Rosyidah, \& Purnomo, 2017; Qori'ah, Sholichah, Purnomo, \& Rosyidah, 2017). Tips mengelola institusi wirausaha adalah niat mendidik dan berjuang karena Allah ta'ala. Niscaya rintangan sebesar apapun akan terasa ringan dihadapan kita (Yuniarti, Kautsari, Sholichah, Purnomo, \& Rosyidah, 2017).

\section{Terbuka untuk Pengalaman Baru}

Bijaksana dan pantang menyerah dalam belajar dan berwirausaha adalah kunci kesuksesan hidup dan wirausaha (Nahdiyah, Amrina, Purnomo, \& Rosyidah, 2017). Setiap manusia yang memiliki ilmu termasuk ilmu wirausaha selayaknya harus mengamalkan ilmu tersebut (Asitah, Usmawati, Rosyidah, \& Purnomo, 2017). Tidak ada yang mencapai sesuatu yang hebat dengan tetap berada di zona nyaman mereka. Sebagai wirausaha yang bercita-cita tinggi, penting untuk melakukan peregangan di luar zona nyaman Anda dan tetap membuka pikiran Anda terhadap ide-ide baru. Biasakan mencari pengalaman baru karena akan memaparkan Anda pada hal-hal, 
orang-orang dan ide-ide yang akan membantu Anda tumbuh sebagai pribadi (Emerson, 2017).

11. Perlihatkan kepada Audiens Anda bahwa Anda Peduli dengan Membuat Konten yang Bermanfaat untuk Mereka

Peduli banyak tentang komunitas Anda dan konsisten dan buat konten secara teratur yang akan membantu orang, dan Anda akan membangun suku orang yang begitu siap dan bersedia menjadi pelanggan Anda seumur hidup (Basu, 2018).

\section{Berani Ambil Risiko}

Salah satu ciri umum di antara pengusaha sukses adalah mereka tidak takut mengambil risiko. Mereka memahami bahwa risiko yang diperhitungkan seringkali mengarah pada kesuksesan. Bergerak dari menjadi pengusaha yang bercita-cita menjadi benarbenar meluncurkan bisnis akan membutuhkan beberapa lompatan yang diperhitungkan. Anda tidak dapat masuk ke dunia bisnis hanya dengan bermimpi dan berharap tentang hal itu (Emerson, 2017). 


\section{References}

Asitah, N., Usmawati, D. Z., Rosyidah, E., \& Purnomo, A. (2017). MI Hasyim Asy'ari Ilmu Harus Terus Mengarus. In Wirausaha Pendidikan Indonesia (Jilid 2). Sidoarjo: UNUSIDA Press.

Basu, T. (2018). Top 20 Tips for Building a Business from Successful Entrepreneurs. Retrieved June 16, 2019, from https://www.thinkific.com/blog/tips-building-abusiness-successful-entrepreneurs/

DiScala, J. (2017). 8 Essential Productivity Tips for the Busy Entrepreneur. Retrieved June 11, 2019, from https://www.inc.com/johndiscala/8-essential-productivity-tips-for-busyentrepreneur.html

Emerson, M. (2017). 8 Habits to Become a Successful Young Entrepreneur. Retrieved June 10, 2019, from https://succeedasyourownboss.com/8-habitsbecome-successful-young-entrepreneur/ Fidiana, W., Istiana, Z., Rosyidah, E., \& Purnomo, A. (2017). MINU Waru 2 Insan Berkilau Cahaya Manfaat. In Wirausaha Pendidikan Indonesia (Jilid 4). Sidoarjo: UNUSIDA Press. L'Écuyer, J.-P. (2016). Ten Tips to Becoming a Better Entrepreneur. Retrieved June 12, 2019, from https://www.futurpreneur.ca/en/2016/ten-tipsto-becoming-a-better-entrepreneur/ 
Maula, I., Mufidah, F. I., Rosyidah, E., \& Purnomo, A. (2017). SD Antawirya Islamic Javanese School Mother is Culture. In Wirausaha Pendidikan Indonesia (Jilid 1). Sidoarjo: UNUSIDA Press.

Mérineau, É. (2017). 17 tips for first-time entrepreneurs in 2017. Retrieved June 12, 2019, from https://medium.com/@etiennemerineau/17tips-for-first-time-entrepreneurs-in-2017e98cda59aa41

Munjidah, A., Zannah, I. P. N., Purnomo, A., \& Rosyidah, E. (2017). MI Thoriqussalam Berpegang Kepada Rosul. In Wirausaha Pendidikan Indonesia (Jilid 4). Sidoarjo: UNUSIDA Press.

Nahdiyah, K., Amrina, S., Purnomo, A., \& Rosyidah, E. (2017). SD Taman Pendidikan Islam Porong Iman Kuat Bekal di Akhirat. In Wirausaha Pendidikan Indonesia (Jilid 2). Sidoarjo: UNUSIDA Press.

Purnomo, A. (2017). Pengertian Edupreneur. https://doi.org/10.31227/osf.io/8fnu6

Qori'ah, S., Sholichah, S. A., Purnomo, A., \& Rosyidah, E. (2017). Progresif Bumi Sholawat dengan Kebenaran Semua Pasti Ada Jalan. In Wirausaha Pendidikan Indonesia (Jilid 3). Sidoarjo: UNUSIDA Press.

Setyawati, I., Purnomo, A., Irawan, D. E., Tamyiz, M., \& Sutiksno, D. U. (2018). A Visual Trend of Literature on Ecopreneurship Research Overviewed within The Last two Decades. Journal of Entrepreneurship Education, 21(4), 1-7. Retrieved from https://www.abacademies.org/articles/a- 
visual-trend-of-literature-on-ecopreneurshipresearch-overviewed-within-the-last-twodecades-7468.html

Sholichah, S. A., Istiqomah, A., Rosyidah, E., \& Purnomo, A. (2017). MI Darun Najah Berfikir Berkarya Berdzikir. In Wirausaha Pendidikan Indonesia (Jilid 3). Sidoarjo: UNUSIDA Press. Yuniarti, D., Kautsari, M. F., Sholichah, F., Purnomo, A., \& Rosyidah, E. (2017). SMP SMA Al-Amin Ponpes Bahrul Hidayah Serahkan pada Allah Ta'ala. In Wirausaha Pendidikan Indonesia (Jilid 1). Sidoarjo: UNUSIDA Press. 